\title{
Promoting meal planning through mass media: awareness of a nutrition campaign among Canadian parents
}

\author{
Melissa Anne Fernandez ${ }^{1,2}$ (1), Sophie Desroches ${ }^{1,2}$, Marie Marquis ${ }^{3}$, \\ Alexandre Lebel ${ }^{4,5,6}$, Mylène Turcotte ${ }^{2}$ and Véronique Provencher ${ }^{1,2, *}$ \\ ${ }^{1}$ School of Nutrition, Université Laval, Quebec, Quebec, Canada: ${ }^{2}$ Institute of Nutrition and Functional Foods, \\ Université Laval, Pavillon des Services, Quebec, Quebec, Canada, G1C 0A6: ${ }^{3}$ Department of Nutrition, Université \\ de Montréal, Montreal, Quebec, Canada: ${ }^{4}$ Graduate School of Land Management and Urban Planning, Université \\ Laval, Quebec, Quebec, Canada: ${ }^{5}$ Evaluation Platform on Obesity Prevention, Quebec Heart and Lung Institute, \\ Quebec, Quebec, Canada: ${ }^{6}$ Centre for Research on Planning and Development (CRAD), Université Laval, Quebec, \\ Quebec, Canada
}

Submitted 10 December 2018: Final revision received 21 June 2019: Accepted 3 July 2019: First published online 30 October 2019

\begin{abstract}
Objective: To evaluate awareness of the Eat Well Campaign (EWC) among parents and assess perceptions about its effectiveness.

Design: Post-campaign evaluation study with a cross-section of parents recruited through random digit dialling. Participants completed an online survey about EWC awareness, its perceived effectiveness among parents and their meal planning practices (attitudes, behaviours and self-efficacy).

Setting: A federal mass-media campaign disseminated by Health Canada (2013-2014) to promote meal planning to Canadian parents.

Participants: Parents ( $n$ 964) of children aged $2-12$ years from all Provinces and Territories.

Results: Of respondents, $41 \%$ (390/964) were aware of the campaign; Quebec City and rural Quebec had the highest rates of awareness, whereas Vancouver, Winnipeg and Toronto had the lowest. Awareness was greater among parents with lower income, basic education and French-speakers. Campaign intensity was significantly associated with greater odds of reporting positive attitudes towards the EWC and meal planning $(P<0.05)$. Campaign awareness was significantly associated with greater odds of believing that meal planning helps maintain a healthy diet $(\mathrm{OR}=1.68,95 \% \mathrm{CI} 1.03,2.74)$ and planning meals (OR $=1 \cdot 66,95 \%$ CI 1·03, 2.54), but not self-efficacy, in adjusted models.

Conclusions: The present study is the first to evaluate an initiative that promoted meal planning with mass media. The EWC demonstrated evidence of success in terms of equitable access to a nutrition initiative by reaching lower-income and less-educated parents. Understanding behavioural factors among different segments of the population will be important to target appropriate audiences and develop tailored interventions that support healthy eating practices.
\end{abstract}

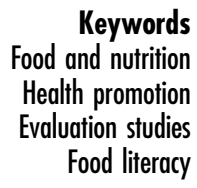

Dietary risk factors contributed to 11 million deaths worldwide in $2017^{(1)}$. In Canada, poor diet is attributed an economic burden of \$CAN 13.8 billion/year in healthcare-related costs, similar to tobacco and greater than physical activity $^{(2)}$. Although challenging, improving dietary intakes of the population is a public health priority and policy strategies that are integrated, multicomponent and involve multiple domains of influence (organizational, community and government) are likely to have a greater reach and be more equitable and sustainable ${ }^{(3,4)}$. Health promotion through mass media is a policy lever that has demonstrated effectiveness through improving dietary intakes by increasing fruit and vegetable consumption and limiting intakes of sodium ${ }^{(5)}$. Successful mass-media campaigns, however, are generally part of multicomponent programmes or comprehensive strategies ${ }^{(6,7)}$. 
Mass-media health education campaigns have the possibility of reaching large proportions of a target population $^{(8)}$ and are expected to have small-to-moderate effects on individuals' health attitudes, knowledge and behaviours, which may translate into major population impacts $^{(9,10)}$. Mass-media health education campaigns are tools used by public health practitioners at government agencies and non-profit organizations to promote healthy behaviours $^{(11)}$. These campaigns have four key elements in common: (i) achieve a specific outcome (e.g. change in health attitudes); (ii) target a large number of people; (iii) have a defined time frame; and (iv) use organized communication channels and activities (e.g. newspapers, television, posters $)^{(12)}$. While hygiene campaigns have demonstrated incredible success by increasing hand washing by $50 \%$ in Ethiopia over a 3 -year period ${ }^{(13)}$, a $5 \%$ change in behaviour is considered a realistic benchmark for a successful mass-media campaign ${ }^{(14)}$. To achieve this level of success, however, campaigns need to reach a high level of exposure for audience recall and awareness ${ }^{(15)}$. Research suggests that saturation coverage, i.e. campaign intensity and frequency, are the most important components for effecting behaviour change ${ }^{(13)}$.

Campaign evaluation research is indispensable to driving the field of health communication forward ${ }^{(11)}$. The purposes of evaluating the outcomes of a mass-media health education campaign are to determine whether it achieved its set objectives, determine what worked well and what needs further improvement, and determine learning points to inform and improve future campaigns ${ }^{(16)}$. In physical activity promotion, campaign awareness, measured by the number of messages recalled, was associated with greater pedometer use in the 'Canada on the Move' initiative ${ }^{(17)}$. In a sexual health campaign, respondents aware of the 'Get Yourself Tested' campaign were more likely to report engaging in the behaviours promoted $^{(18)}$. Awareness of the nutrition campaigns 'Five A Day' and 'Fruits and Veggies - More Matters' was associated with greater odds of consuming at least five servings of fruits and vegetables daily ${ }^{(19)}$. Nutrition campaigns that have been evaluated have generally focused on promoting fruit and vegetable consumption and in some cases sodium, fat or sugar reduction ${ }^{(3)}$. Little is known about the impacts of mass-media interventions promoting other dietary practices ${ }^{(5)}$. A key barrier to healthy eating and food preparation is time, and dietary practices such as meal planning are thought to be viable solutions to facilitate healthy eating ${ }^{(20-24)}$.

The Eat Well Campaign: Food Skills (EWC) was a Canadian mass-media campaign that promoted family meal planning and preparation to Canadian parents. The overall objective of the present study was to evaluate the EWC among a cross-section of Canadian parents with an online survey. We hypothesized that the EWC reached the majority of Canadian parents and improved their perceptions and practices about meal planning. Specific aims included determining: (i) the awareness, intensity and frequency of the EWC; (ii) differences in awareness according to parents' sociodemographic characteristics; (iii) perceptions about the EWC's effectiveness; (iv) the effect of the EWC's intensity and frequency on perceived effectiveness; and ( $v$ ) the associations between EWC awareness and meal planning attitudes, behaviours and self-efficacy.

\section{Methods}

\section{Campaign description}

The EWC was a multicomponent healthy eating and education awareness initiative developed by Health Canada (a federal health agency) to promote family meal planning to parents of children aged 2-12 years. The EWC had belief, education and behavioural components that aligned with the following objectives: (i) increase the number of Canadians who believe it is important to plan meals; (ii) increase the number of Canadians who believe it is important to involve family in meal planning; (iii) provide Canadians with information related to meal planning skills; (iv) increase the number of Canadians who are knowledgeable about how to plan meals; and (v) increase the number of Canadians who plan meals. The campaign was disseminated in English and French throughout the country by Health Canada over a year (2013-2014) with the help of cross-sector partners from the retail food industry, media and health organizations to increase its reach and effectiveness ${ }^{(25)}$. It included a comprehensive set of strategies to deliver nutrition messaging to Canadian parents using multiple channels (television, print, online, food retail outlets and public health offices) along with a toolbox of resources for health professionals. While the campaign focused on meal planning, other nutrition messaging was disseminated concurrently. For the purpose of the present study, the evaluation was limited to objectives around meal planning messaging and the key campaign elements that were disseminated through mass media. These elements included bilingual public service announcements with the 'Mr. Zucchini' cartoon character, which were disseminated online, in food retail outlets and in store flyers, but may have also been shared by regional public health offices (see online supplementary material, Supplemental File S1, for an example). Editorials and infographics were published monthly in two popular women's print magazines (Coup de Pouce in French and Canadian Living in English). Vignettes with two celebrity families (Saskia Thuot in French and The Wilsons in English) were televised on Canadian cable networks. Two campaign spokeswomen (Isabelle Huot for Frenchspeakers and Christine Cushing for English-speakers) made public appearances and starred in vignettes that appeared on social media. Finally, editorials were produced for websites in both languages (e.g. Huffington 
Post). Campaign messages were developed to accommodate different media channels, be seasonally appropriate and easily adaptable by partner organizations. Health Canada tested key campaign visuals and messages with focus groups prior to launching the campaign. While Health Canada was engaged in the entire research process, the research team was independent and not involved in the development or in the implementation of the EWC. For these reasons, the evaluation study could not be integrated into the EWC and data collection began towards the end of the campaign.

\section{Recruitment and data collection}

A representative sample of Canadian parents was recruited by a professional recruitment firm using random digit dialling. Recruitment began at the end of the EWC in late March 2014 and continued until July 2014 when the participant sample from each Province and Territory mirrored population statistics and at least 1100 participants had activated the survey link and responded to key questions about campaign awareness. The desired sample size ( $n$ 1100) was based on estimating campaign reach (awareness) of at least $50 \pm 3 \%$ (OpenEpi.com). The inclusion criteria were: adults aged $\geq 18$ years, Canadian citizens, parents with at least one child (aged $2-12$ years), living with child(ren) at least $50 \%$ of the time, being responsible for meal preparation at least $50 \%$ of the time, understanding French or English, having access to the Internet and having a valid email address. Parents who met inclusion criteria and agreed to be included in the study were emailed consent forms and a link to a webbased survey by the recruitment firm. If the survey was not completed within two weeks of dispatching the email, members of the research team would then send a maximum of three follow-up reminders to all participants by email and/or telephone. The survey closed at the end of August 2014. Consent was given by activating the link to the survey. Parents who completed surveys were entered into a draw to win one of three iPads. Surveys included three questionnaires that collected: (i) standard sociodemographic characteristics; (ii) data on recognition of EWC elements and perceived effectiveness of the campaign; and (iii) questions about meal planning from a general food literacy questionnaire. These questionnaires were designed by the research team to assess the impacts of the EWC.

\section{Description of variables}

Reach

Campaign reach (awareness) was defined as the recognition of at least one of five key campaign elements presented ('Mr. Zucchini' caricature, vignettes with celebrity families, magazine editorials, spokeswomen and web editorials). Unaware parents were defined as having no recall of any campaign elements presented. Campaign intensity was determined on a scale of $1-5$ with each integer representing the number of campaign elements recognized. Campaign frequency was defined as the number of times parents reported seeing each campaign element over a 12-month period and is presented as a total monthly average.

\section{Perceived effectiveness}

Only parents who were aware of the campaign responded to the ten statements about attitudes, knowledge and behaviours of the EWC objectives and messaging. These responses were dichotomized. For example, 'a lot more' or 'more' $=1$ (perceived effectiveness = yes) and 'not more nor less' or 'less' or 'a lot less' $=0$ (perceived effectiveness $=$ no). Parents were also asked about their agreement with ten other statements about positive and negative effects of the campaign on themselves and their families (see online supplementary material, Supplemental Table S1). At the end of the questionnaire, aware parents were given the opportunity to comment on the EWC.

\section{Meal planning attitudes, behaviours and self-efficacy}

Three items from a general food literacy questionnaire were used to compare meal planning attitudes, behaviours and self-efficacy between aware and unaware parents: (i) 'Planning makes it possible to eat well by ensuring a range of food choices' (meal planning attitude); (ii) 'I have been planning our family meals' (meal planning behaviour); and (iii) 'I feel very competent in planning our meals' (meal planning self-efficacy; Supplemental Table S1). Responses to these three items were dichotomized.

\section{Data analysis}

Descriptive statistics were used to summarize the overall reach (i.e. campaign awareness, intensity and frequency) and perceived effectiveness (i.e. ten statements about the EWC). The $\chi^{2}$ test was used to determine whether differences existed in awareness according to sociodemographic variables. According to these results, sociodemographic variables with significant differences in awareness were further explored using multiple logistic regression models in relation to each campaign element controlling for sex, age and month the survey was completed. To estimate the geographic dispersion of the EWC's awareness, multilevel analyses were performed using MLwiN 2.25 (Center for Multilevel Modelling, Bristol, UK, 2012). Using 6-unit alphanumeric postal codes, participants' Province of residence was further broken down into a total of forty-nine regions across the country. These regions represented census metropolitan areas (population $>100000$ ), agglomeration areas $(10000<$ population $<100000)$ and rural areas (population $<10000$ ). Due to the small sample size, small towns and municipalities (populations < 10000 ) were 
combined into a single group for each province. For example, rural Quebec contained all participants in the Province of Quebec who did not reside in a census metropolitan area or agglomeration area.

Multiple logistic regression models were used to explore the effect of campaign intensity and frequency on perceived effectiveness. All regression models controlled for age, sex, month survey was completed, dominant official language, Province of residence, ethnicity, income, education and religious affiliation. Campaign intensity and frequency were treated as continuous variables. Finally, multiple logistic regression models tested associations between EWC awareness and self-reported meal planning attitudes, behaviours and self-efficacy. Results were considered statistically significant at $P<0.05$. Statistical analyses were done using the statistical software package SAS version 9.4 (SAS Institute Inc., 2012). Respondent comments were analysed with the qualitative data analysis software NVivo 10 (QSR International Pty Ltd., Victoria, Australia, 2013) using semi-qualitative thematic analysis $^{(26)}$.

\section{Results}

\section{Sample}

A total of 2201 eligible Canadian parents were recruited into the study using random digit dialling and 1293 agreed to participate by activating the survey link. Of participants, only those who completed all relevant survey questions were retained for analysis ( $n$ 964; see online supplementary material, Supplemental Fig. S1). Sociodemographic characteristics of the study population are listed in Table 1.

\section{Reach}

Of 964 parents, 390 (40.5\%; $95 \%$ CI 37.4, 43.6\%) were aware of the EWC, recognizing at least one campaign element. While vignettes were recognized by $51.7 \%$ of aware parents, other elements were also recalled by at least $16 \%$ of aware parents (Table 2). For campaign intensity, $50 \cdot 1 \%$ of aware parents recalled one out of the five elements and less than $1 \%$ recalled all five (Fig. 1). Campaign frequency as a whole was relatively low, with the majority of parents aware of the campaign $(72.9 \%)$ recalling the EWC one or fewer times per month (Fig. 2).

Campaign awareness differed significantly across sociodemographic variables (dominant official language, Province/Territory, ethnicity/culture, income, education and religious affiliation; Table 1). There were significant differences in awareness of individual campaign elements according to different sociodemographic variables, generally indicating greater overall awareness among Frenchspeaking Canadians, Quebec residents, parents with lower income ( $<$ \$CAN 40 000/year) and parents without university education. Parents with lower income had significantly higher odds of awareness of all the campaign elements compared with parents with higher income. Frenchspeaking Canadians had greater awareness of all campaign elements except the web (Table 2). Campaign awareness varied geographically across Canada. Conditional on age, sex, education level and income, $9.8 \%$ of the total variation in EWC awareness was accounted for by region of residence. Among the forty-nine regions, the highest awareness was observed in rural Quebec and Quebec City, while the lowest awareness was observed in Winnipeg, Vancouver and Toronto $(P<0.05$; Fig. 3).

\section{Perceptions about the Eat Well Campaign messages}

Perceived effectiveness of the campaign among parents aware of the Eat Well Campaign

The majority of aware parents reported that it was more important to plan and include family in meal planning. Less than half of parents exposed to the campaign found that the messages were relevant for family meal planning or preparation and even fewer found them useful for family meal planning or preparation. Just under a third of parents reported feeling more knowledgeable about meal planning. Similarly, less than a third actually reported planning more family meals and fewer than a quarter reported cooking more meals (Supplemental Table S1).

Perceived positive and negative impacts of the campaign among parents aware of the Eat Well Campaign

Less than a third of aware parents indicated that the EWC had positive impacts on their families such as making family meals more enjoyable, and a minority of parents reported negative effects of the campaign such as increasing the sense of guilt as a parent (Supplemental Table S1).

Effect of campaign intensity and frequency on perceived effectiveness among parents aware of the Eat Well Campaign

For every additional campaign element that parents recalled (campaign intensity), there were significant increases (i.e. between 35.9 and 109.7\%) in the odds of perceiving that the EWC was effective, for every effectiveness measure reported. Similarly, each additional time per month that parents reported seeing the campaign (campaign frequency) was significantly associated with increased (i.e. between 28.6 and $63.6 \%$ ) odds of perceiving the EWC as effective. The measures for belief and knowledge components, however, were not significant for campaign frequency (Table 3).

\section{Parents' comments about the Eat Well Campaign}

Approximately a third of aware parents (34\%, $n$ 130) left comments about their awareness of, feelings about and 
Table 1 Sociodemographic characteristics of Canadian parents of children aged 2-12 years from all Provinces and Territories, and differences according to Eat Well Campaign (EWC) exposure, April-August 2014

\begin{tabular}{|c|c|c|c|c|c|c|c|}
\hline \multirow[b]{2}{*}{ Variable } & \multicolumn{2}{|c|}{ Total $(n 964)$} & \multicolumn{2}{|c|}{ Exposed $(n 394)$} & \multicolumn{2}{|c|}{ Non-exposed $(n 576)$} & \multirow[b]{2}{*}{$\chi^{2} P$ value } \\
\hline & $n$ or mean & $\%$ or SD & $n$ or mean & $\%$ or SD & $n$ or mean & $\%$ or SD & \\
\hline Sex & & & & & & & 0.46 \\
\hline Female & 775 & $80 \cdot 4$ & 318 & $41 \cdot 0$ & 457 & $58 \cdot 8$ & \\
\hline Male & 189 & $19 \cdot 6$ & 72 & $38 \cdot 1$ & 117 & 61.9 & \\
\hline Age (mean and SD) & & & & & & & 0.51 \\
\hline Years & $39 \cdot 3$ & $6 \cdot 00$ & $39 \cdot 2$ & $6 \cdot 26$ & 39.4 & $5 \cdot 83$ & \\
\hline \multicolumn{8}{|l|}{ Dominant official language } \\
\hline English & 749 & $77 \cdot 2$ & 252 & 33.6 & 497 & $66 \cdot 4$ & $<0.0001$ \\
\hline French & 221 & $22 \cdot 3$ & 142 & $64 \cdot 3$ & 80 & $35 \cdot 8$ & \\
\hline Provinces and Territories & & & & & & & $<0.0001$ \\
\hline British Columbia & 121 & $12 \cdot 5$ & 33 & $27 \cdot 3$ & 88 & $72 \cdot 7$ & \\
\hline Alberta & 108 & $11 \cdot 1$ & 34 & 31.5 & 74 & 68.5 & \\
\hline Saskatchewan & 27 & 2.78 & 8 & 29.6 & 19 & $70 \cdot 4$ & \\
\hline Manitoba & 33 & 3.40 & 9 & $27 \cdot 3$ & 24 & $72 \cdot 7$ & \\
\hline Ontario & 390 & $40 \cdot 5$ & 144 & $36 \cdot 9$ & 246 & $63 \cdot 1$ & \\
\hline Quebec & 204 & $21 \cdot 2$ & 134 & $65 \cdot 7$ & 70 & $34 \cdot 3$ & \\
\hline New Brunswick & 26 & $2 \cdot 70$ & 9 & 34.6 & 17 & 65.4 & \\
\hline Nova Scotia & 27 & $2 \cdot 80$ & 9 & 33.3 & 18 & $66 \cdot 7$ & \\
\hline Prince Edward Island & 4 & 0.41 & 1 & $25 \cdot 0$ & 3 & $75 \cdot 0$ & \\
\hline Newfoundland & 17 & 1.76 & 5 & 29.4 & 12 & $70 \cdot 6$ & \\
\hline Territories & 7 & 0.73 & 4 & $57 \cdot 1$ & 3 & $42 \cdot 9$ & \\
\hline Ethnicity or culture & & & & & & & 0.02 \\
\hline White & 836 & $86 \cdot 7$ & 349 & 41.5 & 492 & 58.5 & \\
\hline Black & 16 & 1.66 & 11 & $68 \cdot 8$ & 5 & $31 \cdot 3$ & \\
\hline First Nations, Métis or Inuit & 21 & $2 \cdot 18$ & 8 & $38 \cdot 1$ & 13 & 61.9 & \\
\hline Asian & 46 & 4.77 & 10 & $21 \cdot 7$ & 36 & $78 \cdot 3$ & \\
\hline Arab & 15 & 1.56 & 5 & 33.3 & 10 & $66 \cdot 7$ & \\
\hline Other/no answer & 30 & $3 \cdot 11$ & 11 & $35 \cdot 5$ & 20 & $64 \cdot 5$ & \\
\hline Number of children & & & & & & & 0.06 \\
\hline 1 & 184 & $19 \cdot 1$ & 66 & 35.9 & 118 & $64 \cdot 1$ & \\
\hline 2 & 504 & $52 \cdot 3$ & 199 & 39.5 & 305 & 60.5 & \\
\hline 3 & 199 & $20 \cdot 6$ & 84 & $42 \cdot 2$ & 115 & $57 \cdot 8$ & \\
\hline$\geq 4$ & 77 & 7.99 & 41 & $53 \cdot 3$ & 36 & $46 \cdot 8$ & \\
\hline Family structure & & & & & & & $0 \cdot 19$ \\
\hline Two-parent & 845 & 87.7 & 338 & $40 \cdot 0$ & 507 & $60 \cdot 0$ & \\
\hline Single-parent & 76 & $7 \cdot 88$ & 29 & 38.2 & 47 & $61 \cdot 8$ & \\
\hline Step family & 43 & 4.46 & 23 & 53.5 & 20 & $46 \cdot 5$ & \\
\hline Employment status & & & & & & & 0.17 \\
\hline Full-time & 583 & $60 \cdot 4$ & 242 & 41.5 & 341 & 58.5 & \\
\hline Part-time & 167 & $17 \cdot 3$ & 54 & $32 \cdot 3$ & 113 & $67 \cdot 7$ & \\
\hline Stay-at-home parent & 152 & $15 \cdot 7$ & 65 & $42 \cdot 8$ & 87 & $57 \cdot 2$ & \\
\hline Unemployed & 24 & 2.49 & 12 & $50 \cdot 0$ & 12 & $50 \cdot 0$ & \\
\hline Other/no answer & 38 & 3.94 & 17 & 44.7 & 21 & $55 \cdot 3$ & \\
\hline Annual income (\$CAN) & & & & & & & 0.006 \\
\hline$<40000$ & 81 & 8.40 & 47 & $58 \cdot 0$ & 34 & $42 \cdot 0$ & \\
\hline $40000-79999$ & 228 & $23 \cdot 7$ & 94 & $41 \cdot 2$ & 134 & $58 \cdot 8$ & \\
\hline$\geq 80000$ & 528 & 54.8 & 197 & $37 \cdot 3$ & 331 & $62 \cdot 7$ & \\
\hline $\bar{N}$ o answer & 127 & $13 \cdot 2$ & 52 & 40.9 & 75 & $59 \cdot 1$ & \\
\hline Level of education completed & & & & & & & $<0.0001$ \\
\hline Primary or secondary & 156 & $16 \cdot 2$ & 79 & $50 \cdot 6$ & 77 & $49 \cdot 4$ & \\
\hline College & 252 & $26 \cdot 1$ & 118 & $46 \cdot 8$ & 134 & 53.2 & \\
\hline University & 556 & $57 \cdot 7$ & 193 & 34.7 & 363 & $65 \cdot 3$ & \\
\hline Religious affiliation & & & & & & & 0.002 \\
\hline Christian & 619 & $64 \cdot 2$ & 278 & 44.9 & 341 & $55 \cdot 1$ & \\
\hline Other faith & 57 & $5 \cdot 91$ & 18 & $31 \cdot 6$ & 39 & 68.4 & \\
\hline None & 244 & $25 \cdot 3$ & 82 & 33.6 & 162 & $66 \cdot 4$ & \\
\hline No answer & 44 & 4.56 & 12 & $27 \cdot 3$ & 32 & $72 \cdot 3$ & \\
\hline
\end{tabular}

suggestions for the EWC. Among comments, the most frequent theme $(n 47)$ identified was the perception that the campaign had no impact: '.. it has had NO influence on my eating habits or meal preparation.' The second most identified theme ( $n$ 46) was that parents did not feel they were really aware of the EWC despite having recognized some campaign elements: 'I just remember seeing the Wilson's on TV but I honestly do not recall ever hearing of this Eat Well Campaign or seeing it anywhere.' The next most frequent themes indicated that planning ( $n 24)$ and 


\section{$\mathbf{N S}$ "Public Cealth Nurrition}

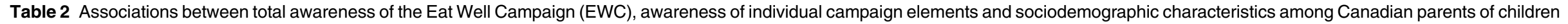
aged 2-12 years from all Provinces and Territories ( $n$ 964), April-August 2014

\begin{tabular}{|c|c|c|c|c|c|c|c|c|c|c|c|c|}
\hline & \multicolumn{2}{|c|}{ EWC† } & \multicolumn{2}{|c|}{ 'Mr. Zucchini' } & \multicolumn{2}{|c|}{ Magazinesł } & \multicolumn{2}{|c|}{ Vignettes } & \multicolumn{2}{|c|}{ Spokeswomen } & \multicolumn{2}{|c|}{ Web } \\
\hline & OR§ & $95 \% \mathrm{Cl}$ & OR§ & $95 \% \mathrm{Cl}$ & OR§ & $95 \% \mathrm{Cl}$ & OR§ & $95 \% \mathrm{Cl}$ & OR§ & $95 \% \mathrm{Cl}$ & OR§ & $95 \% \mathrm{Cl}$ \\
\hline Awareness (\%) & \multicolumn{2}{|c|}{40.5} & \multicolumn{2}{|c|}{$30 \cdot 3$} & \multicolumn{2}{|c|}{41.6} & \multicolumn{2}{|c|}{$51 \cdot 7$} & \multicolumn{2}{|c|}{33.5} & \multicolumn{2}{|c|}{$16 \cdot 4$} \\
\hline Dominant official language (Ref. = English) & & & & & & & & & & & & \\
\hline \multicolumn{7}{|l|}{ Region (Ref. $=$ Ontario) } & $3 \cdot 74^{\star \star \star}$ & $2 \cdot 61,5 \cdot 35$ & $9 \cdot 77^{\star \star \star}$ & $6 \cdot 33,15 \cdot 1$ & $0.44^{*}$ & $0.20,0.97$ \\
\hline British Columbia & $0.62^{*}$ & $0.64,1.00$ & $1 \cdot 18$ & $0.60,2 \cdot 30$ & 0.62 & $0.35,1.12$ & 0.60 & $0.31,1.15$ & 0.42 & $0.16,1 \cdot 10$ & 0.69 & $0.30,1.60$ \\
\hline Prairies & 0.73 & $0.49,1.08$ & 0.79 & $0.41,1.52$ & 0.79 & $0.48,1.30$ & 0.88 & $0.53,1.46$ & $0.36^{\star}$ & $0.15,0.89$ & 0.82 & $0.41,1.64$ \\
\hline Quebec & $3 \cdot 28^{\star \star *}$ & $2 \cdot 27,4.48$ & $2 \cdot 36^{\text {** }}$ & $1.44,3.88$ & 1.17 & $0.75,1.82$ & $3.73^{\star \star *}$ & $2.48,1.46$ & $7 \cdot 27^{\star \star \star}$ & $4.54,11.7$ & $0.42^{*}$ & $0.19,0.95$ \\
\hline Maritimes and North & 0.90 & $0.54,1.49$ & 1.39 & $0.67,2.86$ & 0.50 & $0.23,1.07$ & $1 \cdot 10$ & $0.58,2.90$ & 0.26 & $0.06,1.11$ & 0.40 & $0.12,1.34$ \\
\hline \multicolumn{13}{|l|}{ Ethnicity (Ref. = Caucasian) } \\
\hline Other & 0.78 & $0.53,1.15$ & $0.47^{*}$ & $0.22,0.99$ & $1 \cdot 18$ & $0.74,1.91$ & 0.80 & $0.48,1.32$ & 0.91 & $0.50,1.62$ & 0.95 & $0.44,2.06$ \\
\hline \multicolumn{13}{|l|}{ Annual income (Ref. $=\geq \$ C A N 80000)$} \\
\hline$<40000$ & $2 \cdot 26^{\star * *}$ & $1.40,3.66$ & $1.97^{*}$ & $1.07,3.66$ & $1.91^{*}$ & $1 \cdot 10,3 \cdot 34$ & $1 \cdot 76^{*}$ & $1.03,3.00$ & $2 \cdot 44^{\star *}$ & $1.37,4.37$ & $2.39^{*}$ & $1.14,5.00$ \\
\hline $40000-79999$ & 1.14 & $0.83,1.57$ & 0.71 & $0.42,1.20$ & 0.96 & $0.62,1.48$ & 1.44 & $0.98,2.10$ & 1.29 & $0.82,2.03$ & 0.62 & $0.29,1.31$ \\
\hline No answer & 1.15 & $0.77,1.71$ & 1.17 & $0.65,2.08$ & 1.33 & $0.85,2.25$ & 1.00 & $0.61,1.66$ & 1.08 & $0.81,2.04$ & 1.31 & $0.63,2.74$ \\
\hline \multicolumn{13}{|c|}{ Level of education completed (Ref. = University) } \\
\hline Primary or high school & $1.90^{\star *}$ & $1.32,2.73$ & 1.60 & $0.99,2.61$ & 1.00 & $0.61,1.63$ & $2 \cdot 08^{\star *}$ & $1.35,3.20$ & $2 \cdot 26^{\star \star}$ & $1.38,3.72$ & 1.38 & $0.68,2.77$ \\
\hline College & $1.64^{\star *}$ & $1 \cdot 21,2 \cdot 23$ & 0.82 & $0.50,1.35$ & 1.27 & $0.86,1.88$ & $2 \cdot 11^{\star \star \star}$ & $1.47,3.04$ & $2 \cdot 26^{\star *}$ & $1.47,3.48$ & 1.45 & $0.81,2 \cdot 61$ \\
\hline \multicolumn{13}{|l|}{ Religious affiliation (Ref. $=$ Christian) } \\
\hline Other faiths or no beliefs & $0.60^{\star \star}$ & $0.46,0.80$ & $0.64^{*}$ & $0.42,0.99$ & 0.78 & $0.54,1.12$ & $0.64^{\star}$ & $0.45,0.91$ & $0.54^{\star}$ & $0.35,0.83$ & 0.69 & $0.39,1.22$ \\
\hline
\end{tabular}

Ref., reference category.

${ }^{\star} P<0.05,{ }^{* \star} P<0.005,{ }^{* \star *} P<0.0001$ based on logistic regression models.

†Awareness of the EWC is defined as recall of at least one of the campaign elements presented.

†Poor model fit.

$\S$ Model adjusted for age, sex and month the survey was completed. 


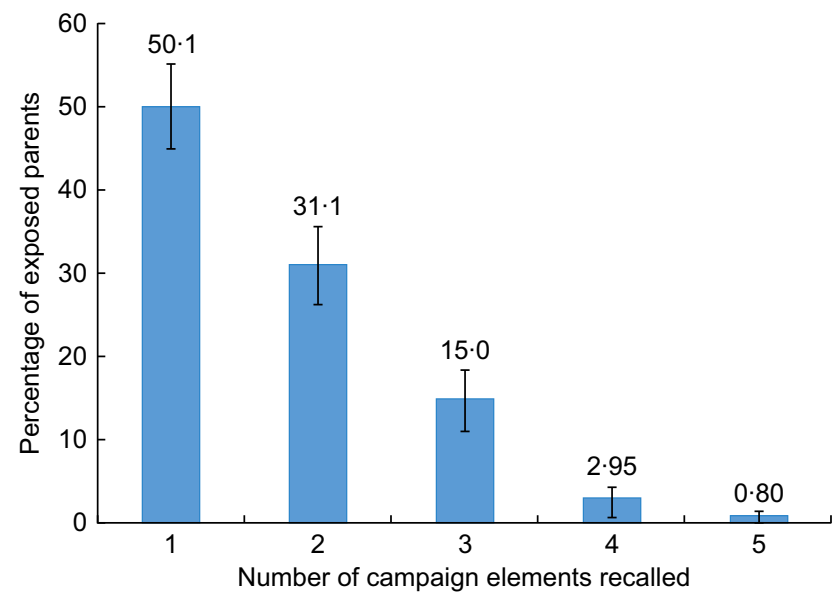

Fig. 1 (colour online) Campaign intensity. The number of different Eat Well Campaign elements recalled by Canadian parents $(n 390)$ of children aged $2-12$ years from all Provinces and Territories, April-August 2014. Values are percentages with their $95 \%$ confidence intervals represented by vertical bars

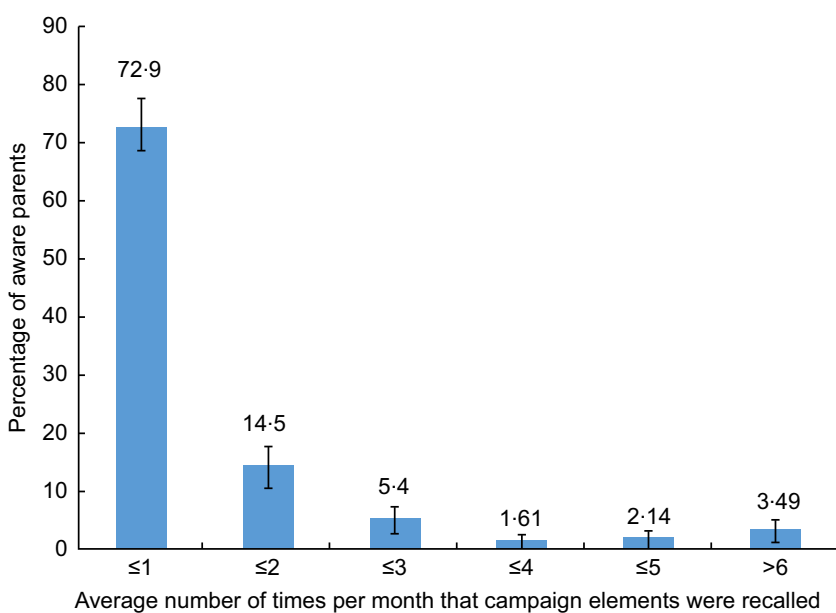

Fig. 2 (colour online) Campaign frequency. The average number of times per month that Canadian parents of children aged 2-12 years from all Provinces and Territories recalled the Eat Well Campaign over the course of a year (n390), April-August 2014. Values are percentages with their $95 \%$ confidence intervals represented by vertical bars

healthy eating ( $n$ 23) behaviours were already present among some parents aware of the campaign (see online supplementary material, Supplemental Table S2).

\section{Meal planning attitudes, behaviours and self- efficacy}

Campaign awareness was significantly associated with greater odds of believing that meal planning helps maintain a healthy diet (meal planning attitudes) compared with parents not aware of the EWC, OR $=1.68$ (95\% CI 1.07, 2.65). This relationship remained significant even after adjusting for multiple potential confounders, i.e. age, sex, language, region, ethnicity, family type, employment, income, education and month the survey was completed, $\mathrm{OR}=1.68$ (95\% CI 1.03, 2.74). Campaign awareness was not initially significantly associated with greater odds of planning more meals (meal planning behaviours), $\mathrm{OR}=1.41$ (95\% CI 0.96, 2.07); however, the relationship became significant after controlling for multiple potential confounders, OR $=1.66$ (95\% CI 1.03, 2.54). Associations between campaign awareness and feeling competent to plan meals (self-efficacy) were not significant in crude (OR $=1.12 ; 95 \%$ CI $0.82,1.55)$ or fully adjusted models $(\mathrm{OR}=1 \cdot 21 ; 95 \% \mathrm{CI} 0 \cdot 86,1 \cdot 71)$.

\section{Discussion}

Overall, the EWC did not reach the majority of Canadian parents; however, it was particularly effective in reaching French Canadians and parents with basic education and lower income. While the latter two groups are traditionally harder to reach, it appears that the mass-media strategies used to deliver the EWC were successful in this case. French Canadians tend to view Canadian-based French content ${ }^{(27)}$ that is potentially very concentrated (with highly recognizable 'local' celebrities), whereas English media in Canada is diluted with American, foreign and online competitors, which may explain the greater awareness among French-speakers. Campaigns disseminated via mass media may be very effective in reaching Frenchspeakers but may have less capacity to penetrate English-speaking audiences. Of promotional strategies, television vignettes appeared to be the most recalled delivery channel. However, they reached only half of parents indicating that other dissemination channels cannot be neglected. Nevertheless, televised vignettes were particularly effective in reaching parents with basic education and lower income ( $<\$ C A N 40000)$. It can be speculated that this finding may indicate that these groups are higher consumers of conventional television. The rates of conventional television use are, however, declining across the country, particularly among younger Canadians (18-34 years), in favour of Internet viewing ${ }^{(27)}$. These potentially rapidly changing trends in traditional media use need to be considered when planning future massmedia campaigns.

The variation in campaign awareness in cities across Canada showed that the campaign may not have been overly successful in penetrating parents living in large cosmopolitan cities such as Toronto and Vancouver. These differences may be due to potentially different media usage patterns or demographics in regions across Canada. Differences in reach across sociodemographic groups reinforce the need for formative research and the importance of audience segmentation prior to campaign development to identify the most appropriate communication strategies with messages tailored to specific groups $^{(28)}$. A recent systematic review of social marketing 


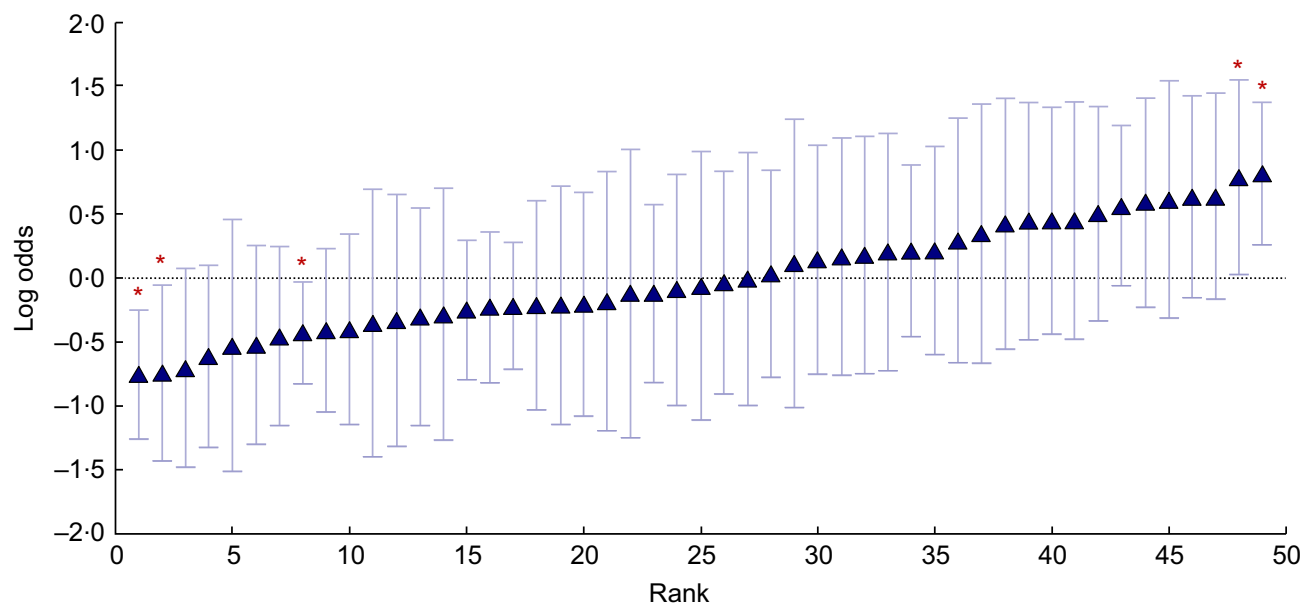

Fig. 3 (colour online) Caterpillar plot of Canadian census metropolitan, agglomeration and rural areas ranked by awareness of the Eat Well Campaign (EWC) from least aware (left) to most aware (right), April-August 2014 ( $n$ 909). Each $\boldsymbol{\Delta}$ represents the mean of a different census metropolitan, agglomeration or rural area, with the $95 \%$ confidence interval represented by a vertical bar. From left to right, the ten places in Canada that were the least aware of the EWC were: Vancouver, BC $(n 64)^{\star}$, Winnipeg, MB $(n 25)^{*}$, rural Alberta ( $\left.n 16\right)$, Hamilton, ON (n22), Saskatoon, SK $(n 16)$, rural British Columbia $(n 23)$, Toronto, ON $(n 141)^{*}$, Calgary, ON ( $n 31)$ and Halifax, NS (n19). From right to left, the ten places in Canada that were the most aware of the EWC were: rural Quebec $(n 47)^{\star}$, Quebec City, QC $(n 17)^{\star}$, London, ON (n14), Laval, QC $(n 15)$, Gatineau, QC $(n 7)$, Terrebonne, QC $(n 13)$,

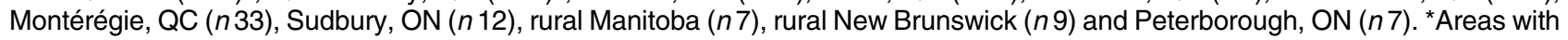
significantly greater odds of having different awareness of the EWC than the Canadian average (log odds $=0.0)$ are indicated by $95 \%$ confidence limits that do not cross the average. Only parents who provided valid 6-unit postal codes associated with an identifiable Canadian city or town were included in the model. Adjusted multilevel model controlled for age, sex, education and income $(P<0.05)$

Table 3 Associations between campaign intensity, campaign frequency and measures of perceived effectiveness of the Eat Well Campaign (EWC) among aware Canadian parents of children aged 2-12 years from all Provinces and Territories (n390), April-August 2014

\begin{tabular}{|c|c|c|c|c|}
\hline & \multicolumn{2}{|c|}{ Campaign intensity† } & \multicolumn{2}{|c|}{$\begin{array}{l}\text { Campaign } \\
\text { frequency }\end{array}$} \\
\hline & OR§ & $95 \% \mathrm{Cl}$ & OR§ & $95 \% \mathrm{Cl}$ \\
\hline Believed it was more important to plan as a result of the EWC & $1 \cdot 77^{\star \star}$ & $1.32,2.35$ & $1 \cdot 21$ & $0.98,1.48$ \\
\hline $\begin{array}{l}\text { Believed it was more important to include family in meal planning as } \\
\text { a result of the EWC }\end{array}$ & $1 \cdot 73^{\star \star \star}$ & $1 \cdot 30,2 \cdot 30$ & $1 \cdot 17$ & $0.95,1.44$ \\
\hline Felt more knowledgeable about meal planning as a result of the EWC & $1 \cdot 67^{* \star *}$ & $1 \cdot 27,2 \cdot 19$ & 1.17 & $0.69,1.43$ \\
\hline Planned more as a result of the EWC & $1.79^{\star \star \star}$ & $1 \cdot 36,2 \cdot 35$ & $1 \cdot 32^{*}$ & $1.09,1.60$ \\
\hline Cooked more family meals as a result of the EWC & $1.97^{\star \star \star}$ & $1.46,2.66$ & $1.42^{\star *}$ & $1 \cdot 15,1.75$ \\
\hline Felt campaign messages were relevant for planning my family's meals & $1.36^{\star}$ & $1.05,1.75$ & $1 \cdot 37^{\star \star}$ & $1.12,1.67$ \\
\hline Felt campaign messages were relevant for preparing my family's meals & $1.47^{\star *}$ & $1.13,1.91$ & $1 \cdot 27^{\star}$ & $1.06,1.56$ \\
\hline Felt campaign was useful for planning my family's meals & $1 \cdot 39^{*}$ & $1.06,1.84$ & $1 \cdot 40^{\star *}$ & $1.14,1.72$ \\
\hline Felt campaign was useful for preparing my family's meals & $1.49^{\star \star}$ & $1.13,1.95$ & $1.45^{\star \star \star}$ & $1.17,1.78$ \\
\hline Have discussed the campaign with friends and family & $2 \cdot 10^{\star \star \star}$ & $1.47,2.99$ & $1 \cdot 64^{\star \star \star}$ & $1 \cdot 29,2 \cdot 80$ \\
\hline
\end{tabular}

${ }^{\star} P<0.05,{ }^{\star \star} P<0.005,{ }^{* \star} P<0.0001$ based on logistic regression models.

†Campaign intensity was defined as the number of campaign elements recalled.

$\ddagger$ Campaign frequency was defined as the number of times per month the campaign was recalled over the course of a year.

$\S$ Controlled for age, sex, month the survey was completed, dominant official language, region, ethnicity, income, education and religious affiliation.

interventions suggested that programmes using segmentation are better positioned to influence their audience ${ }^{(29)}$.

The EWC reached a substantial proportion of parents ( $40.5 \%$ ); however, adequate exposure of the campaign may not have been attained. The majority of parents reported awareness of only one out of the five campaign elements and indicated a very mild campaign frequency $(\leq 1 /$ month). The fleeting awareness to the EWC is in part corroborated by comments from parents indicating that despite being exposed to the campaign they did not feel they were aware or impacted by it. The effectiveness of an intervention is linked to the strategies used to implement it. Only $39 \%$ of Health Canada's partners that were interviewed for the process evaluation reported having a 
national presence ${ }^{(25)}$, suggesting that the campaign dissemination may be geographically concentrated in regions where partners had a greater presence/influence. The EWC implementation barriers and facilitators have been reported elsewhere and support parents' comments about not being overly aware of the campaign ${ }^{(30)}$. In fact, Health Canada's partners who helped disseminate the campaign had criticisms over the appropriateness of the campaign strategy as well as questioned its visibility. Partners doubted the EWC's ability to penetrate the target population and effect behaviour change(30). High campaign exposure does not automatically translate into the high campaign awareness that is necessary for a media campaign to be effective $^{(31)}$. Greater EWC intensity (number of elements exposed) was significantly and positively associated with perceived effectiveness among parents, which reinforces the importance of adequate campaign visibility and awareness. Health Canada's partners reported the lack of resources as a prominent barrier to the EWC implementation, particularly financial resources ${ }^{(30)}$. While mediamethod approaches have been shown to be effective in altering dietary practices ${ }^{(32)}$, increased funding will allow for the use of multiple media channels and longer campaign duration to improve awareness, intensity and frequency of media messages ${ }^{(10)}$.

The perceived effectiveness was relatively high for belief components and low to moderate for knowledge and action components. These results indicate that parents generally perceived the EWC to be successful in increasing awareness in the importance of meal planning, but fewer parents reported believing that the campaign was useful, provided adequate knowledge or helped them plan more. Nevertheless, campaign awareness was associated with significantly greater, but modest, odds of reporting better attitudes towards planning meals and engaging in planning meals, but there were no differences in self-efficacy when all covariates were included in models. These results are supported by a meta-analytic review measuring the effectiveness of mass-media health campaigns, which found that mass-media methods were successful in changing behaviours and knowledge but not self-efficacy ${ }^{(14)}$. To improve self-efficacy through mass-media campaigns, instructional material such as brochures or celebrity spokespeople could be used ${ }^{(14)}$.

The results also indicate that despite perceptions of lack of awareness, the EWC provided some evidence of positive associations between campaign awareness and meal planning attitudes. Nevertheless, cursory exposure to the EWC was likely insufficient to promote significant behaviour change among parents. While attitude and behaviour components were reportedly improved over the short term, persistent changes in behaviour components need more time and repeated exposure ${ }^{(33)}$. Mass-media or paid advertising campaigns can be extremely successful in promoting small changes in health behaviour; however, successful interventions have focused on a small number of specific behaviours (e.g. choosing $1 \%$ milk instead of whole milk) and not multiple complex behaviours (e.g. education and awareness of planning and family meal preparation). Broad campaigns of limited duration that target multiple behaviours are not thought to be highly successful ${ }^{(3)}$. While nutrition education alone is insufficient to effect behaviour change ${ }^{(34)}$, multicomponent health promotion strategies that include mass-media campaigns with focused messaging have reported successes in promoting healthy eating at both national and community levels ${ }^{(5)}$.

\section{Strengths and limitations}

The present study was a third-party post-intervention evaluation of the EWC; therefore, the research team was not involved in its planning and had little knowledge about the intervention's rationale and design. It was not possible to collect pre-campaign data to compare participants before and after the intervention and the context of the evaluation study did not allow for the use of existing validated questionnaires. Additionally, it was not possible to determine whether associations between awareness and meal planning attitudes and behaviours were attributed to the EWC or other residual confounding factors such as initial interest in the topic.

Reach was defined as recall of at least one of the five campaign elements presented, which provided a good indication of awareness but remains an estimation dependent on recall. To consider differences in recall, we controlled for the month that parents responded to the survey (April-August 2014) in logistic regression models. The parents sampled were representative of the different regions in Canada; however, as a group they were more educated, composed of more two-parent families and less ethnically/culturally diverse than the general population. The study topic could have created a sampling bias by recruiting parents who were more engaged and interested in healthy eating or a social desirability bias; therefore, parents may be more likely to recognize and recall the campaign elements and report positive beliefs regarding meal planning. Given the specific context of the EWC, results cannot be generalized to other campaigns or populations. However, the results will be useful to help public health practitioners and decision makers improve communication strategies to reach parents.

\section{Future work}

Evaluations should be an integral part of campaign development to monitor short-term health attitudes and behaviours as well as longer-term health outcomes. Future government campaigns need to incorporate evaluation into intervention planning to ensure that the outcomes are clearly defined, measurable, focused on behaviour change and aligned with evaluation objectives ${ }^{(35)}$. An integrated robust evaluation designed concurrently with the 
intervention will also minimize biases, confounding factors and concerns about establishing causality by providing opportunities to collect longitudinal data from both an exposed and a comparison group to evaluate specific campaign objectives over time ${ }^{(36)}$.

Future campaigns may be more effective if they employ simple and consistent messaging by focusing on a single behaviour rather than attempting to influence multiple dimensions of eating practices at the same time (e.g. meal planning and family involvement in meal planning) ${ }^{(3)}$. Furthermore, pre-campaign consumer-oriented research (i.e. formative research) with a sound basis in behaviour change theory is essential to ensure messages are tailored to the appropriate audiences. Social marketing strategies may provide guidance to refine and tailor mass-media campaigns. Finally, to maximize awareness and subsequently induce behaviour change, significant investments should be made to increase campaign duration, intensity and frequency ${ }^{(37)}$.

Results from the present study provide valuable insight into the reach and effectiveness of a multichannel massmedia intervention that promoted family meal planning. The study supports the importance of evaluating and reporting public health campaign outcomes, ideally by an independent body that will submit research findings to peer review, in a transparent and objective manner. In addition to incorporating an evaluation component into health communication interventions, public health practitioners are encouraged to carefully plan interventions by conducting formative research, including collecting baseline data, to judiciously select key messages, audiences and the most appropriate behaviours to change prior to launching potentially costly mass-media campaigns.

\section{Conclusion}

The present study is the first to evaluate a mass-media campaign that promoted meal planning as a solution to overcome time-related barriers to healthy eating. Despite limitations, as a mass-media campaign, the EWC demonstrated evidence of success in terms of equitable access to a nutrition initiative by reaching lower-income and less-educated parents. While confounding factors remain, positive associations between campaign awareness and positive attitudes towards meal planning are supported by three sources of data in the present study: (i) subjective perceptions of effectiveness by the majority of aware parents who reported it was important to plan and include family in meal planning; (ii) increased odds of parents believing it was important to plan meals and planned more meals with greater campaign intensity; and (iii) an objective comparison between aware and unaware parents indicating aware parents had greater odds of believing meal planning helps maintain a healthy diet. From an independent research perspective, these findings support the need for formative research to understand underlying behavioural factors, audience diversity and how to effectively reach different segments of the population, which will be key to move forward with new campaigns, particularly in countries with non-homogeneous populations such as Canada.

\section{Acknowledgements}

Acknowledgements: The authors would like to thank Health Canada for sharing key information and providing input into this study. They would also like to thank Pierre Gagnon for support validating statistical analyses. Financial support: This work was supported by the Canadian Institutes of Health Research (CIHR; funding reference number GIR-127078). M.A.F. was a CIHR Fellow (funding reference number MFE-152525). The CIHR was not involved in designing the study or interpreting the data. Conflict of interest: None. Authorship: M.A.F., S.D., M.M., M.T. and V.P. contributed to study conception and design. M.A.F. and M.T. were involved with data acquisition. M.A.F. and A.L. were involved in data analysis and/or interpretation. M.A.F. drafted the article. All authors were involved in critically revising the manuscript for important intellectual content and have provided final approval of the version submitted. Ethics of human subject participation: This study was conducted according to the guidelines laid down in the Declaration of Helsinki and all procedures involving human subjects were approved by the Comité d'éthique de la recherche avec les êtres humains de l'Université Laval (\#2013-055) and the Comité d'éthique de la recherche en santé de Université de Montréal (\#13-118-CERES-R). Electronic informed consent was obtained from all participants.

\section{Supplementary material}

To view supplementary material for this article, please visit https://doi.org/10.1017/S1368980019002957

\section{References}

1. Afshin A, Sur PJ, Fay KA et al. (2019) Health effects of dietary risks in 195 countries, 1990-2017: a systematic analysis for the Global Burden of Disease Study 2017. Lancet 393, 1958-1972.

2. Lieffere JRL, Ekwaru JP, Ohinmaa A et al. (2018) The economic burden of not meeting food recommendations in Canada: the cost of doing nothing. PLoS One 13, e0196333.

3. Mozaffarian D, Afshin A, Benowitz NL et al. (2012) Population approaches to improve diet, physical activity, and smoking habits a scientific statement from the American Heart Association. Circulation 126, 1514-1563.

4. Mozaffarian D, Angell SY, Lang T et al. (2018) Role of government policy in nutrition - barriers to and opportunities for healthier eating. BMJ 361, k2426. 
5. Afshin A, Penalvo J, Del Gobbo L et al. (2015) CVD prevention through policy: a review of mass media, food/menu labeling, taxation/subsidies, built environment, school procurement, worksite wellness, and marketing standards to improve diet. Curr Cardiol Rep 17, 98.

6. World Health Organization (2014) Global Status Report on Noncommunicable Diseases 2014. Geneva: WHO.

7. Torok M, Calear A, Shand F et al. (2017) A systematic review of mass media campaigns for suicide prevention: understanding their efficacy and the mechanisms needed for successful behavioral and literacy change. Suicide Life Threat Behav 47, 672-687.

8. Rudov L, McCormick-Ricket I, Kingsmill D et al. (2017) Evaluation recommendations for nonprofit social marketing campaigns: an example from the Louisiana Campaign for Tobacco-Free Living. Int J Nonprofit Volunt Sect Mark 22, e1570.

9. Noar SM (2006) A 10-year retrospective of research in health mass media campaigns: where do we go from here? J Health Commun 11, 21-42.

10. Wakefield MA, Loken B \& Hornik RC (2010) Use of mass media campaigns to change health behaviour. Lancet $\mathbf{3 7 6}$, 1261-1271.

11. Noar SM, Harrington NG \& Helme DW (2010) The contributions of health communication research to campaign practice. Health Commun 25, 593-594.

12. Atkin C \& Salmon CT (2010) The Handbook of Communication Science. Thousand Oaks, CA: SAGE Publications, Inc.; available at http://sk.sagepub.com/ reference/hdbk_commsci (accessed April 2018).

13. Head R, Murray J, Sarrassat $S$ et al. (2015) Can mass media interventions reduce child mortality? Lancet 386, 97-100.

14. Anker AE, Feeley TH, McCracken B et al. (2016) Measuring the effectiveness of mass-mediated health campaigns through meta-analysis. J Health Commun 21, 439-456.

15. Wymer WW (2015) Innovations in Social Marketing and Public Health Communication Improving the Quality of Life for Individuals and Communities. Cham: Springer.

16. French J, Blair-Stevens C, McVey D et al. (2010) Social Marketing and Public Health Theory and Practice. Oxford: Oxford University Press.

17. Craig CL, Cragg SE, Tudor-Locke C et al. (2006) Proximal impact of Canada on the Move - the relationship of campaign awareness to pedometer ownership and use. Can J Public Health 97, Suppl. 1, S21-S27.

18. McFarlane M, Brookmeyer K, Friedman A et al. (2015) GYT: Get Yourself Tested campaign awareness: associations with sexually transmitted disease/HIV testing and communication behaviors among youth. Sex Transm Infect 42, 619-624.

19. Erinosho TO, Moser RP, Oh AY et al. (2012) Awareness of the Fruits and Veggies - More Matters campaign, knowledge of the fruit and vegetable recommendation, and fruit and vegetable intake of adults in the 2007 Food Attitudes and Behaviors (FAB) Survey. Appetite 59, 155-160.

20. Lavelle F, McGowan L, Spence M et al. (2016) Barriers and facilitators to cooking from 'scratch' using basic or raw ingredients: a qualitative interview study. Appetite 107, 383-391.
21. Jabs J \& Devine CM (2006) Time scarcity and food choices: an overview. Appetite, 47, 196-204.

22. Fulkerson JA, Kubik MY, Rydell S et al. (2011) Focus groups with working parents of school-aged children: what's needed to improve family meals? J Nutr Educ Behav 43, 189-193.

23. Aube J \& Marquis M (2011) Attitudes and habits of Canadians in relation to planning and preparing meals at home. Can J Diet Pract Res 72, 70-75.

24. McIntosh WA, Kubena KS, Tolle G et al. (2010) Mothers and meals. The effects of mothers' meal planning and shopping motivations on children's participation in family meals. Appetite 55, 623-628.

25. Fernandez M, Desroches S, Turcotte M et al. (2016) Factors influencing the adoption of a healthy eating campaign by federal cross-sector partners: a qualitative study. $B M C$ Public Health 20, 904.

26. Dixon-Woods M, Agarwal S, Jones D et al. (2005) Synthesising qualitative and quantitative evidence: a review of possible methods. J Health Serv Res Policy 10, 43-53.

27. The Canadian Radio-television and Telecommunications Commission (2016) Communications monitoring report 2016. Her Majesty the Queen in Right of Canada. https:// crtc.gc.ca/eng/publications/reports/PolicyMonitoring/2016/ cmr.pdf (accessed August 2018).

28. Rootman I, Goodstadt M, Hyndman B et al. (editors) (2001) Evaluation in Health Promotion: Principles and Perspectives. Copenhagen: WHO Regional Office for Europe.

29. Firestone R, Rowe CJ, Modi SN et al. The effectiveness of social marketing in global health: a systematic review. Health Policy Plan 32, 110-124.

30. Fernandez M, Desroches S, Marquis M et al. (2017) Facilitators and barriers experienced by federal cross-sector partners during the implementation of a healthy eating campaign. Public Health Nutr 20, 2318-2328.

31. Davis KC, Evans WD \& Kamyab K (2013) Effectiveness of a national media campaign to promote parent-child communication about sex. Health Educ Behav 40, 97-106.

32. Reger B, Wootan MG \& Booth-Butterfield S (1999) Using mass media to promote healthy eating: a community-based demonstration project. Prev Med 29, 414-421.

33. Beaudoin CE, Fernandez C, Wall JL et al. (2007) Promoting healthy eating and physical activity - short-term effects of a mass media campaign. Am J Prev Med 32, 217-223.

34. Temple NJ \& Nestle M (2006) Population nutrition, health promotion, and government policy. In Nutritional Health: Strategies for Disease Prevention, pp. 13-29 [NJ Temple, $\mathrm{T}$ Wilson and DR Jacobs Jr, editors]. Totowa, NJ: Humana Press.

35. Craig P, Dieppe P, Macintyre S et al. (2008) Developing and evaluating complex interventions: the new Medical Research Council guidance. BMJ 337, a1655.

36. Magura S (2012) Failure of intervention or failure of evaluation: a meta-evaluation of the National Youth Anti-Drug Media Campaign Evaluation. Subst Use Misuse 47, 1414-1420.

37. Bauman A, Smith BJ, Maibach EW et al. (2006) Evaluation of mass media campaigns for physical activity. Eval Prog Plan 29, 312-322. 